Cilly Müller de IndA

\title{
PERVIVENCIA DE EURÍPIDES EN RACINE, A TRAVÉS DE ANDRÓMACA
}

La humanidad, expectante y azorada, vivió una experiencia imponderable con el lanzamiento de la sonda Voyager II, se gún lo registra el diario La Nación' del 28-VIII-89.

E1 periodista compara a dicha sonda con "una botella arrojada al inmenso océano cósmico" que porta un "festival auditivo" - consistente en saludos en diversas lenguas, sonidos de animales, de la lluvia, de ruidos de motores y hasta de un beso...-, destinado a otras civilizaciones que habrán de recibirlo dentro de cuarenta mil años aproximadamente.

Es indudable, entonces, que, para el cientifico del siglo XX, la voz, en sus diferentes manifestaciones, es la expresión fiel del \бyos de la civilización en la que se encuentra inmerso.

Basándonos en esta relevante experiencia podemos exclamar triunfantes que,.....la tecnología, en simbiosis con el es píritu, ha hecho realidad el pensamiento del filólogo cuyano Vicente Cichitti, con quien tuvimos el honor de departir en va rias ocasiones $y$, en especial, durante el IV Simposio Nacional de Estudios Clásicos realizado en Resistencia en 1976. En la medulosa conferencia que este humanista de corazón pronunciara en oportunidad del desarrollo de sus sesiones y a la que titulara: "Nuevas dimensiones del humanismo", afirma: "...El conocimiento profundo del propio "logos" o "lex" o "dharma", es de cir, la familiaridad con su propio pasado clásico provee $\bar{a} \overline{1}$ 
hobre de los medios para conprender las otras civilizaciomes: religa a cada ser humano a la commidad a la que pertenece y al mismo tienpo lo hace apto para recibir el mensaje de las culturas de otros pueblos. (...)" (p.277) ((1))

$Y$ éste es a muestro entender, el punto crucial de contacto entre Racine y Euripides, hombres que, por no desvincularse de su circunstancia temporal, conscientes de pertenecer a una commidad determinada, pudieron, inmersos en una cmpathía espiritual my honda, entahlar, a través del $\times 6$ yos, una fecunda commión de vivencias.

Dos épocas, la Atenas del siglo - $V$ de Pericles y Versalles del siglo XVII de Luis XIV, en las cuales el hombre se erige en centro de la historia $y$, en pleno dominio de su racio cinio, brinda al mundo un legads imperecedero: la primera, como bien lo esquematiza C.M. Buwra $((2))$, a través " $(.$.$) del$ respeto por el gobierno demorrático (...)" lega por siempre "(...) el respeto por el indivicho, y ésta es la gran contribu ción ateniense para el mundom. (p.241).

la otra, cual vientre genernso, abona la tierra donde habrá de gestarse el postulado revolucionario del siglo XVIII, que of recerá al mundo un hombr te mevo, asentado en el tripode de la libertad, la igualdad y la fraternidad.

No creemos oportumo detemernos en la enmeración de los signos politico-sociales que hicieron posible el macimiento de un arte clásico en el siglo XVII francés. Georges Duby y R. Mandrou ((3)) los explicitan en síntesis inobjetable.

Tampoco abundaremos en las referencias que Highet ((4)) o Saint Beuve ((5)) consignan respecto a la formación cultural de los escritores de la época que nos ocupa.

Debenxus si recalcar que, en ese entorno, el mundo grecommano proporcionó los temas de inspiración y las formas a las que las obras se adecuaron, con pervivencia fuerte del valor cathártico de la tragedia clásica.

El espíritu greco-latino acompañará de aquí en adelante, la prédica revolucionaria. Y mientras la pol ítica se obsti nará en abolir el pasado, el arte retornará gustoso a los mode los clásicos, manantiales insaciables de su inspiración.

Con este suscinto pantallazo, vayamos a los autores se- 
leccionados. Respetando el orden cronológico empezaremos por Eurípides (485 a.J.C. ó 480 a.J.C. - 407 a.J.c. ó 405 a.J.C.) Teniendo en cuenta su producción, que se desarrolla a partir del 455 a.J.C., debe ser ubicado en la segunda mitad del siglo V a.J.C..

"(...) Representa todas las tendencias actuantes en una Atenas que ha comenzado a declinar en su esplendor (...)" (Carlos Disandro) ((6)).

Trágico "psicológico", al decir de Schlessinger ((7)); incomprendido por sus contemporáneos; adel antado a su época, arhiere a las "novedades intelectuales" y no puede ceñirse a moldes que lo constriñan.

Andrómaca es una pieza descuidada; escrita pasiblemente -de acuerdo con la opinión de críticos autorizados-, con finalidad de propaganda política: se hace eco de la patriótica indignación ateniense contra Esparta debido a la disputa que ambas ciudades sostenían por la posesión de un territorio ubicado al noroeste de Atenas, durante la guerra del Peloponeso (431 a.J.C. - 421 a.J.C.).

Daremos sólo algunas pautas de la obra en las que nos apoyaremos para el análisis de la obra de Racine. No hacemos hincapié en el argumento, el que, obviamente, es conocido por todos.

El autor ubica la acción en Tesalia, en el Santuario de Tetis, diosa que, para Wilamovitz ((8)) (p.90-91), da unidad a la obra, pues ésta empieza y termina en su presencia.

El personaje central es Andrómaca, viuda de Héctor y es clava concubina de Neoptólemo con quien tiene un hijo,Molosso.

A propósito de esta figura es interesante recordar que Homero en Ilíada nos la presenta en su carácter de espasa. Al nombrarla, es imposible dejar de evocar la desgarrante despedi da de los esposos que el poeta of rece en el canto $i$ y que fué ra plasmada en la pintura lacerante de Giorgio de Chirico en 1962: Héctor y Andrómaca, dos maniquíes sin sexo pero con profundos sentimientos. La soledad que los rodea es presagio de la merte que los acosa.

Hecha esta disgresión, continuamos con el texto de Eurí pides: el prólogo inicial, expositivo, pone en antecedentes dé 
los hechos ocurridos y revela la situación presente.

Explota el autor la rivalidad entre una bárbara y una griega (tema que también aparece en Medea), aunque en la trage dia que nos ocupa, los celos anidan en la griega Hermione, esposá de Neoptólemo (Recordaremos a propósito que dicho dato aparece constatado por Homero en el canto $\Delta$ de Odisea).

La unidad de acción se corta en el verso 765 (aunque la obra posee 1288 versos), pueś, como destaca nuestro eminente filólogo Antonio Tovar (op.cit., p.89), a partir de dicho verso (y desaparecida la protagonista), el autor entrelaza temas: a) el conflicto amoroso entre Hermione y Orestes, personaje és te que nada tiene que ver con el asunto en cuestión pero que corta el nudo. Actúa, al decir de Tovar, de owthp;

b) la muerte de Neoptólemo y

c) la apoteosis de Peleo.

La presencia del deus ex machina, Tetis en este caso, resuel ve el conflicto desde el exterior.

Los efectos teatrales son patéticos, tales los que produ ce la figura de la madre cautiva, a quien Hermione ultraja con gozo: v.v. 261- 263-

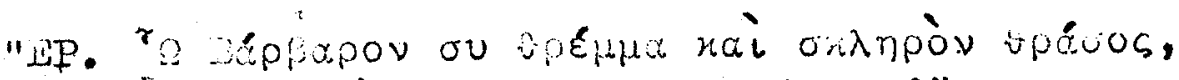

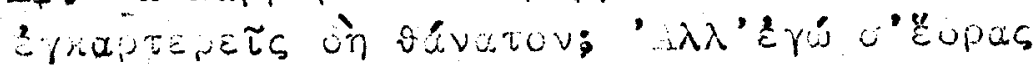

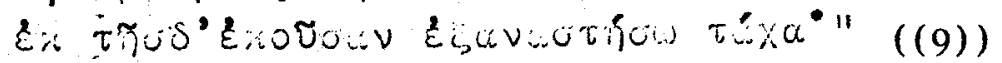

"Oh criatura bárbara y de dura obstinación! Resistirás a la muerte? Mas yo te haré levantar pronto y voluntariamente de este asiento." (Traduc. de A. Tovar, op. cit.).

Los personajes aparecen desmitificados puesto que pinta a los hombres como los ve, con grandezas y errores. Sus criatu ras, según Tovar, son "átomos ingolidarios" (op.cit. p. XXV), piezas que no pueden dividirse.

Eurípides gusta de 10 exótico, como lo evidencia el relato de la muerte de Neoptólemo o la vida inmortal que Tetis promete a Peleo.

No hay jroparubs : la línea trágica se quiebra y el final feliz llega para cada personaje; Andrómaca reinará en el país de los Molossos con Heleno: Hermione huye, inesperadamen- 
te arrepentida, con Orestes; Peleo es recompensado por Tetis con la inmortalidad.

Inclusive la muerte de Neoptólemo es un justo castigo de Apolo, a quien éste ofendiera pero que se consuma sin que la víctima entienda el por qué.

El éxodo, que coincide con el de Medea, Alcestis y Las Bacantes, retoma el tema de la fuerza del Destino que es decre to inevitable de los dioses.

Cómo resuelve Racine (1639-1699) este caudal mítico? Por 1o que Oswald Spengler ( (10)) 11ama "pseudomorfosis" o sea la recreación, en una cultura, de una forma de actividad creada por otra cultura distante en tiempo y espacio". (pág. 14, op.cit.).

De su vida sólo aludiremos a aquello que tiene relación con el tema que nos interesa. Fue educado en Port-Royal-des -Champs donde tuvo acceso a los clásicos.

Su amistad con Boileau, quien,al decir de Saint Beauve, "le animaba en toda pasajera desesperanza y le incitaba, a fuerza de severidad, a que realizara ininterrumpidos progresos. Este contralor incesante de Boileau habría sido funesto, sin duda, para un autor de genio libre (...); a Racine le resul tó provechoso (...). El mismo Boileau se gloriaba de haber enseñado a Racine el hacer "difícilmente versos fáciles" (...)" (p. 196, op.cit.).

Ingresa en la Academia en 1672 lo que demuestra la seriedad de su formación intelectual y su aceptación sin discusión de las reglas de las unidades.

En 1667 se presenta Andrómaca, obra que marca el inicio de los diez años gloriosos, hasta Fedra en 1677.

Él personalmente dirigió la puesta en escena y su éxito fue comparable al de El Cid de Corneille, en 1636.

En el primer prefacio ((11)) explica que el tema ha sido tomado de Eneida de Virgilio, L.III, vv 292-332.

Y dice Racine: "He aquí, en pocos versos, todo el tema: allá el lugar de la escena; la acción que sucede en ella, los cuatro principales actores $y$ aun sus caracteres. Excepto el de Hermione."

Virgilio se adapta a la tradición de Eurípides, con la 
que no coincide Racine pues: su Andrómaca no sufre la suerte de las cautivas ni da a luz a Molosso.

- Pirro renuncia al matrimonio con Hermione, por Andrómaca.

- Orestes no mata a Pirro. En consecuencia: el tema de Eneida es diferente del de Racine.

En ese primer prefacio expresa Racine que ha hecho un acuiprdo entre la tradición y los poetas, dos fuerzas, dice "más ricas que las cronologias".

En el segundo prefacio $((12))$, cita nuevamente a Virgilio como su inspirador y recalca que el Mantuano no ha seguido a Eurípides.

Aclara que ha agregado el desvarío de Hermione y lo confronta con Andrómaca y Astiánax.

Los dos prefacios se complementan, aunque difieren de tono: uno es polémico y el otro, una justificación del escritor, quien se arroga el derecho de ser original y se defiende de haber incluido audacias de sentimientos.

Con respecto a la obra en sí La acción, en la corte -no podemos olvidar'que no faltan los confidentes, ante quienes los personajes desnudan su interior-, y todo el ambiente, las costumbres y la lengua acusan el refinamiento del Versalles de Luis XIV.

Sólo basta ver actuar a Pirro y escucharlo para saber que estamos ante un caballero gentil y galante, (Acto $1^{\circ}$, esce na $\left.4^{\circ}\right)((13))$, aunque su figura of rece contrastes que lo hacen un torpe, fiero y brusco conquistador (Acto $2^{\circ}$, escena $5^{\circ}$ ).

Coincidimos plenamente con Tovar (op. cit. pág. 96) en

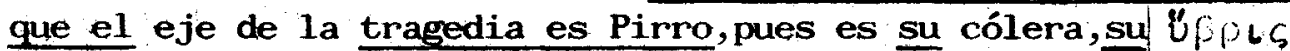
la que desencadena la acción dè los otros. Alrededor de él, otros conflictos amorosos contrapuestos: Andrómaca desprecia a Pirro y él la desprecia.

E1 hijo amenazado es Astiánax, el de Héctor, 1o que vuelve más patética la trama.

Cuando se abre el telón, las pasiones ya están desatadas y sólo falta la resolución del conflicto. Desde el diálogo inicial entre Orestes y Pílades sabemos que Orestes hace seis meses que ha perdido a Hermione, su prometida,y que Troya ha caído 
hace un año.

Los caracteres, esculpidos minuciosamente. No hay referencia ni datos físicos de sus criaturas.

Héctor, que no aparece en la obra, es gravitante en ella, tanto es así que exaspera a Pirro el hecho de que su esposa lo nombre continuamente pues da la sensación de que siguiera a su lado.

Es interesante destacar que uno de los críticos de Raci ne cuenta que en la edición de la Ilíada manejada por él, en el canto , v.398, anotó: "Ella está poseida por Héctor".

Andrómaca, imagen de la fidelidad, fuerte y segura; su apariencia, acorde con su época, es la de una gran dama, in teligente y altiva. Confluyen en ella el amor de esposa y el de madre. Pirro le ofrece la disyuntiva trágica: "Hay que reinar o perecer" (esc. $7^{\circ}$ del acto $3^{\circ}$ ), aunque lógicamente, hace alusión a la muerte de su hijo muy querido.

Existe en ella una dualidad de sentimientos en conflicto pues reconoce las bondades de Pirro y si bien no quiere agradarlo, tampoco desea desagradarlo totalmente.

No odia a la persona de Pirro, pues a su muerte cumplirá su voluntad: reinará en el Epiro.

Es la única que sobrevive integra pues la inspira una voluntad clave y firme, que la sostiene todo el tiempo.

Hermione: ciegamente enamorada de Pirro, se vuelve egoís ta, mezquina y mentirosa. Se vale de Orestes y no escatima medios para consumar su venganza.

El odio se da en ella porque no consuma su amor y tiene la hidalguía de sus mayores, puesto que es hija de un rey.

Sentimos en ella el grito de la amante despechada y el tuteo lo remarca: "Acaso no te he amado, cruel?" (Acto $4^{\circ}$, escena $\left.5^{\circ}\right)$ (v. 1356).

No puede soportar ni entender la muerte de su amado Pirro a quien ella misma trama matar y se abalanza contra Orestes: "Habla: De su suerte ¿quién te hizo el árbitro? Por qué asesinarlo? Quién te 10 ha dicho?". (Escena $3^{\circ}$, acto $5^{\circ}$ ) (v. 1540).

El grito del suicia1o termina con este personaje absolutamente trágico. 
Orestes es el caballero pusilánime a quien no se le da siquiera la oportunidad de matar a su rival pues los griegos, ábalanzados sobre Pirro, le ganan de mano.

Lo importante es que él aparece en toda la pieza, desprendido de su pasado mítico; en ningún momento se alude al hecho de que es un matricida y aquí vuelve a presentárselo como inocente.

He ahí que dirá, en su locura, aquellos versos inmortales, modelos de aliteración. "Para quién son esas serpientes que silban sobre nuestras cabezas?" (v. 1638 del acto $5^{\circ}$, esc. $5^{\circ}$ ) "Pour qui sont ces serpents qui sifflent sur vos têtes?"

Obra elaborada y pulida según el propio código exigente de Racine: "Mis escenas ligadas, mi tragedia está hecha", lo que coincide con la preceptiva aristotélica que considera que la planificación de una obra es más difícil que su misma ejecuición.

Diferencias ostensibles entre Euripides y Racine: No re petiremos las ya apuntadas en la exposición; sólo remarcaremos las que, a nuestro entender marcan una toma de postura de los autores:

- En Eurípides, el decreto del Destino determina la suerte de los hombres.

- En Racine, el amor está colocado por encima de la fatalidad.

- El griego desmitifica a sus personajes con el deseo de acercarlos a sus contemporáneos y produce caricaturas. za euripidea.

- El francés crea caracteres, despojándolos de la crude

\section{CONCLUSIONES:}

En ambos autores, el resorte lírico, conmovedor y profundo, es eje predominante. Los dos son humanistas; lo que vale es el Hombre, con sus pasiones y miserias, el hombre eterno, sacado de un tiempo y de un espacio determinados.

La recurrencia hecha por Racine en su Andrómaca demuestra que "la carga mitopoética es (al decir de Luis Gil), altamente pregnante," ((14)) "análoga al proceso de la transmisión de la vida." 
Ante Eurípides y Racine, dos pintores de mujeres que hi cieron realidad el sueño de Cichitti -el encuentro de culturas a través del mito, que es otra forma de decir "palabra"- cabrí an aquellos versos de Borges que María Kodama cita sin saber si lo hace con fidelidad en la tierna declaración de amor que le hiciera, en ocasión de que el 24-VIII-89, Borges hubiera cumplido noventa años y que apareciera en el suplemento litera rio de La Nación del 28-VIII-89: "Qué importa el tiempo sucesí vo si en él hubo una plenitud, un éxtasis, una tarde?". 


\section{BIBLIOGRAFÍA}

1) CICHITTI, Vicente: Nuevas dimensiones del humanismo en: Actas del IV Simposio Nacional de Estudios Clásicas,U.N.N.E., Fac. de Humanidades, Rcia., 1977.

2) BOWRA, C. M.: La Atenas de Pericles. Traducción de Alicia Yllera, Alianza Editorial, Madrid, 1983.

3) DUBY, Georges - MANDROU, Robert: Historia de la civilización francesa. F.C.E. México, 1966.

4) HIGHET, G.: La tradición clásica. F.C.E., México, 1954.

5) SAINTE - BEUVE: Retratos literarios. Traducción de Oscar An drieu. Estrada, Bs.As., 1947.

6) DISSANDRO, Carlos: Introducción a: Obras dramáticas de Eurí pides. El Ateneo, Bs.Ás., 1966.

7) SCHLESSINGER, E.: El Edipo Rey de Sófocles. Inst. de Lenguas Clásicas. U.N. La Plata, 1950.

8) Cita de Antonio Tovar en su Introducción a: Eurípides. Tragedias. Texto revisado y traducido por A. Tovar, volumen I, Alma Mater, Barcelona, 1955.

9) EURIPIDE: Hipoolyte, Andromaque, Hécube. Texte établi et traduit por Louis Méridier. Tomo IT. Les Belles Lettres, Paris, 1965 .

10) SPLENGLER, Oswald. Cita de Highet, G. Tomo II de La tradición clásica (op. ci.t. ant.)

11)RACINE: Théatre Complet. Suivi d'un choix de ses épigrammes concernant son théatre avec unè préface, des notices et des notes par Maurice Rat. Editions Garnier Fréres, Paris, 1953.

12)RACINE: Théatre Complet. (op. cit. ant.)

13)RACINE, Jean: Fedra, Andrómaca, Británico, Ester. Traducción de Nydia Lamarque. Losada, Bs.As., 1944.

14)GIL, Luis: Transmisión mitica. Barcelona, Planeta. 